\title{
PRESENT AND FUTURE TRENDS IN GRASSLAND RESEARCH IN NEW ZEALAND
}

\section{CORKILL}

\section{Grasslands Division, DSIR, Palmerston North}

PASTURE PRODUCtion is logically measured in terms of grazing animals supported by that pasture. A simple calculation based on stock numbers and area in grassland in New Zealand shows that over the last forty years carrying capacity has increased from 1.4 to 3.2 "sheep units" per acre, or $130 \%$ (N.Z. Official Year Book).

Obviously many factors have contributed to this increase, including improved stock and stock management practices, as well as improved pasture plants, pasture nutrition, and pasture management. Present carrying capacity, however, is well below that of which pastures are capable. Brougham and Glenday (1959) have reported an annual yield of 22,000 lb dry matter per acre from a ryegrass/clover pasture without high fertilizer application, irrigation, or applied nitrogen. On unploughable hill country pastures, Suckling (1959) has obtained yields of $9,000 \mathrm{lb}$ per acre, with more than double that production on stock camps. If fully utilized, these pastures would be capable of carrying from 8 to 19 ewe equivalents per acre (Hutton, 1963). Obviously the average production of both lowland and hill country farms is well below the potential of which they are capable. There are, of course, many reasons for this, both technical and economic.

The fact that practice is not keeping pace with technical knowledge may be a good reason for increasing farm advisory services and improving the economic climate for the 'farmer, but it is no excuse for the grassland scientist to reduce his research effort.

I propose to review briefly some of' the fields in which grassland research is at present being carried out, and the direction it may follow in the future. My comments will be restricted to consideration of grassland research aimed only at increasing the yield, quality and utilization of feed for the grazing animal. This research is concerned with pasture plant improvement, plant nutrition, pasture management and pasture utilization. Obviously, I shall be dealing with grassland research in a narrow sense, for it does not 
include, except indirectly, such topics as soil research, pasture diseases and pests, and animal nutrition and health.

\section{IMPROVED PASTURE PLANTS}

Under New Zealand conditions, conventional pasture species, grasses and legumes, are capable of producing ' high yields per acre of animal products at relatively low cost compared with systems of cropping or hand feeding necessarily used in countries with a less favourable climate. A plant capable of continued high yields per acre under repeated harvesting by the grazing animal has many obvious advantages over other food sources.

Pasture plants are needed which are capable of producing still greater and more sustained yields of herbage of higher nutritive quality than those at present available. This plant breeding objective is as true today as it was 60 years ago when, in Volume 1 of the $\mathbf{N e w}$ Zealand Journal of Agri* culture, the first President of the Grassland Association and the founder of grassland research in New Zealand, A. H. Cockayne (1910), stated the objectives of a pasture plant breeding programme when proposing the establishment of a Plant Breeding Station in New Zealand.

There are now 11 bred varieties of pasture plants in general use. Seven species embracing 5 genera are represented by these varieties - two species of Lolium with hybrids between them, two of Trifolium, and one each of Dactylis, Phleum and Medicago. These represent only a, fraction of the species present in pastures of temperate regions of the world. However, there are relatively few species with the inherent characteristics for sustained high-quality production equal to those at present being investigated, particularly the ryegrasses and white clover. There are few grass genera of temperate climates which can match the genus Lolium in those characteristics required of a plant for sown permanent pastures under New Zealand climatic conditions; characteristics such as ability to establish and produce a vigorous sward rapidly, high annual production with extended seasonal yield, wide adaptability to grazing pressure,' and high nutritive value. Among the pasture legumes, white clover occupies a similar position.

Within these few genera there is still a wide field for 'additional improvement through further selection and. hybridization. There are, however, a few other genera which merit the attention of plant breeders for special purposes, and for use in difficult environments to which the ryegrasses and white clover are not well adapted. Among these are Phalaris, Bromus, Festuca and Lotus. 


\section{INTERSPECIFIC AND INTERGENERIC HYBRIDS}

Interspecific and intergeneric hybridization offers an opportunity of producing entirely new varieties with a combination of desirable characteristics 'from different species and genera. The possible value of hybrids between tall fescue and ryegrasses has long been appreciated, and hybrids have been produced on a number of occasions. At Grasslands Division, Anderson has produced a wide array of hybrids, but, like overseas investigators, still faces the problem of overcoming plant sterility. Barclay has produced a promising variety from crosses between Lotus pedunculatus and L. corniculatus, and Pandey has obtained hybrids from crosses between Trifolium repens and $T$. uniflorum. The genus Bromus, with its wide range of species with different agronomic characters, is worthy of intensive investigation for the development of interspecific hybrid varieties.

\section{NUTRITIVE VALUE}

A field of plant improvement which merits particular attention is that concerned with increase in nutritive value. Information is being accumulated on those plant characteristics which determine nutritive value, and the plant breeder is able to apply this knowledge, at least in some cases, to breeding improved varieties. An example is the use of tests for cellulose content (Bailey, 1964) and leaf strength (Evans, 1964) in breeding for better quality in the ryegrasses, The high nutritive value of Manawa short-rotation ryegrass compared with that of Ruanui perennial ryegrass is a reflection of differences in cellulose content and leaf strength. High- and low-cellulose lines of Ariki ryegrass have been selected and are now being tested to determine differences in nutritive value.

More research on the definition of nutritive quality in terms of chemical composition will no doubt pave the way for further advances in breeding higher quality plants.

\section{NUTRIENT EFFICIENCY}

Species and varieties, and even individual plants within a variety, differ inherently in mineral composition and in the efficiency with which they can utilize soil minerals. Considerable differences occur among plants of the one species in the content of such minerals as calcium, magnesium, potassium, sodium, phosphorus and sulphur. There is evidence, at least with some of these, that mineral content is under genetic control. 
Investigations are being undertaken on the possibility of selecting and breeding varieties on the basis of differences in nutrient uptake and assimilation. The objective in plant improvement may be two-fold: (1) breeding varieties more efficient in the use of certain plant nutrients--i.e., plants that with a given available source of a particular nutrient display improved efficiency in dry matter production, (2) breeding varieties with improved mineral quality in respect to animal nutrition. This may mean selecting for higher content of particular minerals,

It has been estimated that, nationally, fertilizers $(\mathrm{P}, \mathrm{K}$ and $\mathrm{S}$ ) cost New Zealand $\$ 25$ million per year. In spite of this there is no doubt that grassland production in much of the country is severely limited by inadequate plant nutrients, particularly phosphorus. There is no need to emphasize the value of breeding high-producing plants with improved efficiency in utilizing plant nutrients such as phosphorus and nitrogen. It is a plant breeding objective worthy of considerable effort.

The plant cover of many New Zealand acid hill country soils consists of relatively low-producing plants with an absence of legumes. Considerable quantities of phosphate and lime are required to render these soils suitable for vigorous growth of high-producing species of grasses and clovers. It may be possible to select acid-tolerant plants from high-producing species of grasses and clovers more adapted to these conditions than the present varieties.

White clover is a poor competitor for phosphorus compared with grasses. Jackman (1970) has shown that white clover growing in association with browntop in a phosphate-deficient soil required $500 \mathrm{lb}$ of superphosphate for sufficient growth to produce $180 \mathrm{lb}$ of nitrogen per acre, whereas, grown alone, it required only $50 \mathrm{lb}$ of superphosphate for equivalent nitrogen production. As white clover is the basis of high-producing pastures in' New Zealand, the breeding of a variety with improved efficiency in phosphorus utilization would be of considerable significance.

\section{MINERAL QUALITY}

The improvement of the mineral quality of pasture plants as food for the grazing animal is a plant breeding objective to which more attention should be given. The large differences among individual plants of a species in content of such minerals as iodine, copper, magnesium and calcium are a basis for the modification of mineral content by selection. 
Further research on the chemistry and biochemistry of pasture plants and on ruminant metabolism is required to provide more precise definitions of mineral quality and to serve as a basis for selection.

There are many animal disorders which are attributed to harmful excesses or deficiencies in pasture plants-e.g., bloat, hypomagnesemia, and fescue foot. Plant selection and breeding offers a method of overcoming these disorders once the basic nature of the causative agents is known.

The typical New Zealand pasture consisting of a more or less complex mixture of grasses and legumes and other species provides a feed supply for the grazing ruminant normally well suited to its requirements. The large differences among species in their chemical composition normally balance out deficiencies or excesses in individual species, and provide a balanced diet for the grazing animal. But the highest-producing pastures are the simplest in botanical composition. In these the beneficial influence of complexity of botanical composition is lost. The simpler the pasture is botanically, the more essential it is that emphasis is placed on pasture quality as well as quantity.

\section{NITROGEN}

In the conventional grass/clover pasture adequately supplied with nutrients to produce vigorous clover growth, clover is capable of supplying sufficient nitrogen to the associated grasses for high pasture yields. But the ability of the clover plant to supply adequate nitrogen for high pasture production is influenced by such factors as host/ rhizobium relations, the inherent productivity of the clover plant, soil nutrient status and pasture management practices. Huia white clover is well endowed with the characteristics to fill this role; it is capable of relatively high yields, it is adaptable to grazing pressure, shading and grass competition through its ability to modify its growth form in response to these factors and its ability to renew root growth and nodulation rapidly after defoliation. No doubt its effectiveness as a supplier of nitrogen could be improved by selection for greater expression of these characteristics. Research is required on the efficiency of fixation under different levels of mineral nutrition, and on the effect of environmental factors such as light, temperature, season and grazing intensity on nitrogen fixation, and on host/ rhizobium relations.

Even the best of our present pasture legumes may be incapable of supplying adequate nitrogen to enable as- 
sociated grasses to reach the highest yields of which they are capable. To reach these levels, artificial nitrogen may be necessary. Its use has been demonstrated where the requirement is increased pasture production during winter and early spring, but it may have much wider application. No doubt higher and more sustained pasture yields could be obtained by the use of artificial nitrogen with grass alone, for, in general, the better grasses are capable of higher sustained yields than the legumes. (An exception to this generality is the high yield potential of lucerne in parts of Canterbury.) Nevertheless, it is probable that in the main, and in the foreseeable future, the grass/legume association will be the basis of our pastures, for the clover plant has an advantage over grasses in nutritive value, and it is a relatively cheap source of nitrogen.

In the past, very little work has been done in New Zealand on the role of artificial nitrogen in pastures because of its-relatively high cost. However, with world production of nitrogen fertilizers increasing and prices decreasing, there is greater accent on their use. Although it is well established in New Zealand that, in the short term, yields of grass/ clover pastures can be raised by appropriate use of artificial nitrogen, there is need for basic work on the long-term effects of applied nitrogen on yield, pasture composition and rhizobial nitrogen production. Information is needed on the pattern of response to nitrogen at different times of the year over a number of years, and on the integration of the use of artificial and rhizobial nitrogen to obtain maximum and well distributed pasture yields.

\section{ROOTS OF PASTURE PLANTS}

Pasture plants differ considerably in root growth and morphology. These differences may be associated with differences in competitive ability for nutrients, efficiency of water and nutrient uptake, and ability of the plant to withstand grazing pressure.

Evans, at Grasslands Division, has shown that severe defoliation may, within 24 hours, drastically reduce root growth. This may limit pasture growth by reducing nutrient and water uptake, and may decrease resistance to mechanical effects of grazing and to drought.

Future research may provide information of significance to grazing management under high stocking rates, and may provide a basis for plant selection for greater efficiency in nutrient and water uptake. 


\section{PASTURE ECOLOGY}

Maximum pasture yields and livestock production do not necessarily follow the use of genetically high-yielding and nutritious plants adequately supplied with plant nutrients. Conventional pastures consist of a mixture of species and varieties in competition one with the other for light, water and nutrients, and responding differently to the environment in which they are growing. To tap the yield potential of which the pasture is capable, appropriate grazing management is essential, and maximum livestock yields require full utilization of the herba.ge produced. .

Emphasis in pasture research in New Zealand has been on pasture ecology-the reaction of the plant to its environment. Investigation has ranged over a wide field, including seeds mixtures, pasture establishment, nutrition, management and utilization, and has provided basic information on which our present practices in grassland farming have been established.

Recommendations for pasture mixtures have changed over the years from complex mixtures of a number of grasses and legumes to mixtures of few species-a trend which has taken place parallel with the acquisition of knowledge on the requirements of pasture species and varieties, and methods of modifying the environment. in line with the plants' requirements.

There is, of course, a limit to the extent to which the environment can be modified. The individual plants within a pasture plant community are subject to the influence of factors in the environment in which they establish and in the environment imposed upon them by the grazing animal. Considerable work has been done on the influence on pasture performance of plant competition and of such manimposed environmental factors as soil fertility, soil moisture, and frequency and intensity of defoliation; and plant reactions to these factors have been related to plant morphological and physiological characteristics.

Knowledge of the reactions of pasture plants to these environmental factors is fundamental to devising seeds mixtures for different purposes and environments, and to the application of appropriate management practices for the suppression of undesirable species, and the full development of the potential yield of desirable species.

\section{HILL COUNTRY PASTURES}

About one half of the sown pastures in New Zealand are on unploughable hill country. In the main they consist 
of low-producing species. A recent survey by Brougham and Grant of pastures on the wet hill country of the Manawatu region showed that, while browntop was present in $81 \%$ of samples, and white clover in $47 \%$, ryegrsss occurred in only $8 \%$.

Since the advent of aerial topdressing and oversowing, the productivity of the hills has undoubtedly improved. Nevertheless, further improvement would be brought about if the relatively low-producing species characteristic of the wet hill country were replaced by high-producing grasses and clovers.

Clover can be readily established but the establishment and maintenance of grasses is not so easily accomplished, although some success has followed the use of chemicals. Research is required on the many factors which influence the establishment and maintenance of high-producing grasses. Work is required on characterization of the extremely variable hill country environment, on techniques of establishing grasses, on interspecies competition, and on the reaction of species to levels of fertility, stocking intensity and grazing management.

\section{OTHER SPECIES}

In the past, the emphasis in ecological and physiological research has been on the ryegrasses and white clover. Similar work needs to be done on other pasture species and on new bred varieties to determine the role the variety may fill in grassland farmiag, and to define the management factors related to its full exploitation. For example, little detailed knowledge is available on Kikuyu grass, an importation which during the last forty years has, through its aggressiveness, become the dominant plant in many Northland pastures. Its aggressiveness is a defect, its high summer production an attribute; in association with other grasses and legumes it could be a valuable pasture constituent. Studies are required specifically to determine those factors which contribute to its competitive ability and to indicate management practices for its full exploitation as a constituent of high-producing pastures with extended seasonal growth.

\section{PASTURE UTILIZATION}

In grassland farming where pasture is grazed in situ animal production does not equate to plant production, for animal grazing, treading and excreting result in losses of available feed. Preferential and under-grazing result in 
feed wastage, over-grazing in reduced plant yields; treading in reduced yields and changes in botanical composition; and animal excretion, while an integral part of the fertility cycle, may lead to feed losses through rendering pasture unacceptable to the grazing animal.

Considerable research has been done in the past, and is being done at present, on these factors as they influence animal production. It is a field of research where results can be put immediately into farming practice; where treading damage is severe stock are fed off the pasture, where grazing is selective stock concentration is increased. The most direct method of reducing losses caused by the grazing animal is, of course, to keep the animal off the pasture, to take the feed to the animal rather than the animal to the feed. But there are also considerable losses arising from this practice-losses due to the removal of beneficial effects of the animal on pastures and losses due to the cost of the operation.

There is an extensive field for future research on factors which influence the utilization of pasture. Studies on the nature and magnitude of losses are necessary. Further information is required on the effects of animal treading on plant production, leaf losses, pasture composition and soil structure, and the cumulative effect on pasture and animal productivity. The grazing behaviour of animals needs investigation in relation to pasture composition, acceptability, quality and quantity. Information is required on losses due to fouling of pastures from animal treading and excreting, and on the duration of the effects of fouling in relation to acceptability.

Knowledge of the magnitude of losses from incomplete utilization, and the factors which contribute to them, should provide the basis for the development of improved grazing practices and farming systems. It is a field of research which could be immediately applied to farming practice and provide the means of more fully equating the high production of which our pastures are capable into animal products.

\section{CONCLUSION}

Reference has been made to fields of research, aimed at increasing the yield, the quality, and the utilization of feed for the grazing animal. The requirement is for better Pasture plants, and improved plant nutrition, pasture management and pasture utilization. Each line of investigation would be expected to contribute in part to the development of improved farming systems. More experimentation is 
required on a pilot-farm scale in which the interactions between soil, plant and animal can be studied, and research results synthesized into farming systems for the more efficient production of animal products from grasslarid.

\section{REFERENCES}

Bailey, R. W., 1964: N.Z. Jl agric. Res., 7: 496-507

Brougham, R. W.; Glenday, A. C., 1959: N.Z. Jl agric. Res., 2: 283-96. Cockayne, A. H., 1910: N.Z. Il Agric., 1: 234-41.

Evans, P. S., 1964: N.Z. Jl agric. Res., 7: 508-13.

Hutton, J. B., 1963: Proc. N.Z. Inst. agric. Sci., 9: 97-108.

Jackman, R. H., 1970: N.Z. agric. Sci. (in press).

N.Z. Official Year Books, 1928-1968.

Suckling, F. E. T., 1959: N.Z. Jl agric. Res., 2: 488-543.

\section{DISCUSSION}

Asked to comment on the importance of pasture quality and quantity in pasture production, 'microclimate factors in relation to grazing management and the ruminant metabolism of the grazing animal, Corkill said he had made the point that quality was every bit as important as quantity. What was needed was for the biochemists to give a definition of quality so that the plant breeders could breed for that factor. Obviously, management would have an effect on microclimate-e.g., long pasture would produce one entirely different from that produced by short pastures. He agreed that much more work was needed on ruminant metabolism.

Langer asked if comment could be made on the approach used in south-east Queensland for the introduction, testing and management of introduced species with relation to the Northland environment. Corkill replied 'that more than 40 species had been introduced for testing at the Grasslands substation at Kaikohe but, so far, no grass, even Setaria spp., was as good as Kikuyu from the productivity viewpoint. It was possible that some introduced legumes could prove helpful.

Asked by O'Connor if he believed in all-grass farming, Corkill stated that he did because efficiency was the key point and conventional pastures could be grazed by the animal in situ under New Zealand conditions.

Washko (U.S.A.) suggested that the objectives outlined could perhaps be modified in view of experience gained in the recent drought. Corkill replied that there was no great lesson except that the drought had influenced the ability of some plants to survivee.g., Manawa ryegrass. This did not mean that it should be discarded, but that we should still endeavour to breed improved varieties.

Smith (U.S.A.) asked if corn and corn silage could be used in New Zealand. Corkill stated in reply that it was, in fact, used in localities where corn had the potential to give high yields. There might be a place for crops-e\&, on plains to feed stock brought down from the hills. However, the basis of the animal industry would 'still be pastures. 